\title{
Education with Games
}

\author{
Hasan Gunes \\ Turkish Folk Literature Associate Professor \\ Anadolu University \\ Eskisehir, Turkey
}

\begin{abstract}
Rumisays "Yesterday is gone my dear friend. We need to say something new today." We, too, considered that it would be proper to consider "children and games" in a different viewpoint with this perspective. Game is an extremely important event for children. However, unfortunately, this process, which is significant for children, is considered as a waste of time by some adults. In actual fact, game is a means closely affecting the mental, physical and spiritual development of children. Just like the fact that some values cannot be bought with money, there are no equivalent counterparts for the acquisitions achieved through games. Many behaviors that are intended to be taught to children can be taught easily via games. For this reason, in the present study of ours, we wanted to show parents that they can teach some rules to their children by dramatizing. As Salzmann stated, "Game is an important chain that connects the child to the leader". For this reason, parents or educators should consider this method well. Because spending time with children and taking care of them and thinking in the way they think are important privileges.
\end{abstract}

\section{Introduction}

Children's games constitute an important subject in folklore. Although the games are considered as a wasted time, they are extremely important for the mental, physical and spiritual development of children. Children learn how to obey rules, to struggle with problems and solidarity through games, which is a natural way. For this reason, it is necessary to give importance to create playgrounds for children. Television and irregular urbanization have restricted the playgrounds of children; and have caused that children stay at home and move away from society. Children who are locked inside houses, play games according to the rules they define on their own, they acquire the habit of disregarding the rules of other individuals around them. In following processes, they try to implement their own rules rather than the rules of their parents. This creates a chaos in the environment of children. However, the games, which are played with friends, have the feature of raising children in line with order and rules. For this reason, children, who play with their friends and spend time with them, do not have difficulty in following the rules in their houses. This situation shows how important the game is in educational field.

Games may become an educational tool for children who throw food packages to grounds despite warnings, who leave their clothes scattered around, and who resist to eating proper food. It isquite easy to make the same things done through games. With the games we will recommend here, children will perceive their work, which they must do as a game rather than a task. For example, throwing food wrappings behind seats instead of dustbin is a behavior that children often adopt. Parents can write the initials of the names of their children behind the packages to avoid this behavior. This simple process will be very effective in the solutionof this problem. Because, the child who throw packages into places or beneath the seats may be determined,and therefore, even if the child denies it, s/he will have to accept his/her guilt. Applying this in the form of a game will help to maintain order at home, and will contribute to the education of children. Through this and similar other games, the desired rules mayeasily be taught in the framework of a game concept.

The games I will give as examples from my book "Time to Play Now", which I believe will contribute greatly to the education of children, can help provide the order at home. Parents can produce games by using the materials which may be found at home, as in the examples, and in this way, they can teach the behaviors they want to without forcing their children. In other words, parents can speed up the learning process with new games, which they can develop, and easily teach the rules that are difficult to learn by children otherwise.

\section{Find the Sock and Run!}

All of the players sit down. Two children are nominated by counting-out rhyme. All the other players stay on the side except for the selected two players. The moderator of the game scatters socks on the ground, and defines a task. For example, "You mustfetch the slippers in the hall!". 
The players find the sock in the hall by matching them and wear them with the command "Start!". Then,they try to fetch the slippers in the hall. The first player that succeeds in this means that s/he eliminates the other player. In this way, the game continues until the last player by changing the task each tine. The player that remains in the end wins a beautiful award.

\section{Wearing Clothes}

All players sit down in the room.They are divided into two teams, and wait in a row. The game moderator puts trousers, sweaters, jackets, gloves, scarfs and socks in front of each team. With the "Start! command, the players should try to wear the clothes in front of them in the fastest way. The first team member who wear the clothes brings his team a point. When the points are written on the table, the players remove the clothes they wear. With the command "Start!", the players must try to wear the clothes in front of them as fast as possible. The team member that wears the clothes first brings a point to his/her team. When the points are written down, players put off the clothes.

The second player in the line must also try to wear the clothes in front of them in the fastest possible way. The game continues in this way. At the end of the game, the team that wins the most points becomes the winner. Players can be made blindfolded to make the game become harder and add some excitement to the game. The clothes that are used in the game are all folded together after the game.

\section{Put on-Take off Clothes!}

All players sit down in the room and are divided into two teams. The game moderator puts trousers, sweaters and pairs of stockings in the middle of the room for each team. With the command "Start!", the players wear all the clothes in front of them, then take them off, and pass behind the line. The second player in the line comes right away, and quickly puts on the clothes. Players must take care to take off the clothes properly. Otherwise, it may take some time for their friends after them to fold the clothes and wear them. This could be against them as a team. The game continues in this way. At the end of the game, the team players that takes off their clothes at the shortest time win the game. The clothesare then folded and put in their places.

\section{Hang the Clothes!}

Players are divided into two teams and gather in the hall. The number of teams can be increased if the number of players is high. The game moderator calls two players from each team and gives a 3-m rope. The players who take the rope come to the front of their teams and keep their ropes tense. With the "Start!" command, each team tries to latch the clothes in their own baskets. The team that hangs the laundry properly at the shorted time wins the game.

\section{The House Attendant}

The players gather in the room. A player is nominated by counting-out rhyme. The nominated player is declared as the house attendant. As the house attendant, s/he orders all the other players for 5 minutes to clean and arrange the house. Other players must perform these tasks. The player who does not fulfill the given task is penalized. Those who perform their tasks take their chocolates as rewards after 5 minutes. At the end of 5 minutes, another house attendant is determined by the counting-out rhyme. This attendant is also responsible for giving directions to other players for 5 minutes in the same way. A prize must be given at the end of each game. In the second round, a fruit may be given instead of chocolate. The game continues in this way. With this game, children become aware of the order of a house.

\section{Hit the balloon in the middle!}

All the players are divided into two teams, and take their places in the corridor. The game moderator places a balloon in the middle of the corridor, and puts about 10 pairs of socks in front of each team. With the "Start!" command, the players find the pair of each sock in front of them, and fold them together, and make into a ball. With these socks, they try to send the balloon to the field of the other team. The socks that are thrown may be used by two teams. After 3 minutes, the area where the balloon lands loses the game. Children will learn how to gather their socks, and fold them. As the requirement of the game, players must find the socks quickly, and fold them. For this reason, children will learn what they learn more easily in everyday life.

\section{Find the Socks!}

The players are gathered in the room. The game moderator keeps one pair of socks in different parts of the house. With the "Start!" command, all players start to look for socks. Whoever finds both pairs of socks and puts on his/her feet wins the game. The winning player gives the other players a fun penalty. 
This game has two important acquisitions for children. The first one is that children collect socks, and the second one is that they also learn to wear them. Because children usually do not want to collect and wear their socks. With this game, children will learn how to collect and wear their socks.

\section{Finding the Trace}

All players are divided into two teams as A and B. Team A hides an item in the house, and also leaves clues that indicate where it is hidden. For example, the first sign may be the sleeves of a sweater indicating the direction of the hidden item. The second sign may indicates the direction of the hidden item. The third sign may be a sock indicating the direction of the hidden item. With similar clothes, it is made easier for children to find the hidden items without being bored (forks and spoons may be used for the game). Once the tips clues are placed, team B will start searching for the hidden item. If team B finds the hidden item within 3 minutes, Team A folds the clothes that are used as signs and places them. However, if the other team cannot find the hidden item in 3 minutes, team B will pick up the clothes and fold them instead. After the penalty has been realized, team B hides an item and takes some clothes from the closet and leaves clues with them. Only,as the requirement of the rule, the clothes that will be left as clues must be changed in each game. Team A tries to find the item by considering the clues in 3 minutes. If Team A finds the hidden item in 3 minutes, team B must fold the items and remove them. However, if the team does not find the hidden items, s/he must fold the clothes instead. The game continues in this way. Children usually do not place their clothes they take off. Sometimes, they not only place their clothes neatly, but also leave them in the middle of the room. When they are told to tidy the room, they do not tidy their rooms, and they put their clothes around here and there. However, with this game, children will be able to collect and place their clothes themselves. For this reason, children will learn how to fold their own clothes with this game.

\section{Socks Game}

All of the socks are washed and placed in the middle of the room. If the number of socks is low, clean socks are separated and mixed in the middle. With the "Start!" command, all players find the pairs of the socks and fold them. At the end of the game, the team that has the most folded socks wins the game. The loser players put the folded socks to their place.

\section{Folding the Clothes}

All laundry is placed in the middle of the room scattered. With the "Start!" command of the game moderator, all players fold the laundry in the middle on their side.

The player that folds more laundry properly at the end of the game wins the game. The player that wins is rewarded with a food.

The purpose of this game is firstly to collect the clothes of children as well as help their mothers with housework.

\section{Claim!}

All of the players sit in a circle. The game moderator reads various claims, and tells the players how long they must make these claims. For example, "Who can make their beds in 2 minutes?" A candy will be given to whom that can fix it. "Who can empty the dishwasher within 10 minutes?" A bar of chocolate will be given to the one who empties it.

"Who can collect the toys in 3 minutes?" The one who collects them will be given fruit milk. The things they are asked to do especially at home may be given in the forms of a game to children.

Players prefer the claims that are proper for them in turn. If the player becomes successful in his/her claim, the prize must be given to him/her. If s/he does not win, s/he is given a small consolation prize. The moderator may help the players to succeed.

\section{Dancing on Clothes}

All of the players take their own clothes and place them on the ground. When the game moderator plays music, the players dance on their clothes. When the music stops, they fold one arm of their clothes. Of course, the players must not be step outside the clothes during folding.

The player who has accidentally step outside the clothes is eliminated from the game. When music starts again, players start dancing again. When the music stops, they fold the other arm. At the end of the game, the player who folds the clothes in the most proper way with the music playing wins 10 points. The game continues with new clothes. The player who reach 100 points first wins the game. The winning player receives fruit as a reward, and eats it with pleasure. Other players are given a consolation prize. 
The aim of this game is to make children fold their clothes properly and place them neatly.

\section{Scoring a Goal}

Players are divided into two teams; and each team is given a name like "Galatasaray" or "Fenerbahçe". Each team defines a place for it in the room, and this place is considered their castle. The game moderator places laundry that must be folded. With the "Start!" command, each team folds one of the laundries in the middle in a neat way, and puts them in the goal of the opponent team. In this way, the player will score a goal. The player takes another laundry again, folds it, and puts it in the goal of the opponent. The game continues in this way. The laundry in the goal posts is counted after 5 minutes. The team the folds more laundrywins the game. The loser team places the remaining clothes in theirplaces.

Children often do not like folding their clothes after they take off them. With this game, players will learn how to fold their clothes and place them neatly.

\section{Conclusion}

The game contributes to the bringing and educating children, as well as to their physical, spiritual and physical development. With games, children learn to obey the rules of the society, to help each other, to be respectful to people, to integrate with people from different backgrounds, not to break the hearts of their friends, to protect the rights of themselves and their friends, to learn order and cleanliness. When considered in this point, games are not a waste of time, but a way of learning life in a different way.

It is a fact that children learn better by playing and testing. For example, a being that can make decisions in panic is children. Because in a chase game, children escapes from in a panic, while at the same time they can think where to hide, where to go, and where to jump. This is an extremely important mechanism. For this reason, parents must benefit from this power of the game.

With this paper, we wanted to show that parents can give their children some rules they want to teach through games by dramatizing. These highlighted games are just a few examples. Parents can make up similar games by creating or designing to teach the acquisitions that want to convey their children. Instead of merely imposing the rules intended to be acquired by children, these rules can be given more easily through games. This will make both sides become less exhausted.

For this reason, parents or educators must make use of this method. Because the language that is understood most easily by children is the language of games.

\section{References}

Güneş, Hasan. Çocuğun Dünyası. Hayat Yayınları. İstanbul, 2011. Güneş, Hasan. Şimdi Oyun Zamanı. Kök Yayıncılık. İstanbul 2010. 